\title{
LIX.-Note on Wechsler's Method for the Separation of Fatty Acids.
}

By Arthur W. Crosslex, M.Sc., Ph.D.

IN connection with a research on which Professor Perkin and $I$ have been engaged for some time past, a large amount of a complicated mixture of fatty acids had to be dealt with. As is well known, the separation of fatty acids is not an easy task, and in this case recourse was had to most of the known methods of separation, including one described by Max Wechsler (Monatsh., 1893, 14, 462). Wechsler says:-

If, to a mixture of two fatty acids, four-fifths of the caustic soda necessary to neutralise them be added, and the whole is steam distilled, the distillate contains the pure acid of higher boiling point. From the residue left after distillation, a further three-fifths of the acids are set free by the addition of sulphuric acid, and these are distilled off with steam. Finally, the remaining one-fifth of the acids is set free, and in this case the distillate contains the acid of lower boiling point in a pure condition. In support of this view, Wechsler gives details of several experiments, which offer apparently such decisive proof of his statement, that one was influenced to try the method on the mixture 
of acids above alluded to. In no instance wns the result satisfactory, in fact so much the contrary, that it was thought advisable to repeat some of Wechsler's experiments.

After dealing with two instances cited by Wechsler, with results not in accord with those be gave, the whole of his experiments were repeated, and a few additional ones made, in order to give the method a thorough trial.

In the first place, the experiments described by Wechsler were carried out with strict attention to the few details given by him, and as will be seen from the numbers obtained, the first fraction of the distillate does, in some cases, contain the acid of higher boiling point in a nearly pure condition: but in no instance does the last fraction contain the pure acid of lower boiling point.

As in the one example given by Wechsler, in which bad results were obtained, an iso-acid was employed, some experiments were made with iso-butyric, iso-valeric, and iso-hexoic (iso-butylacetic) acids, but in no case were results obtained which agreed with Wechsler's statement, for even when using three molecular proportions of the lower to one of the higher boiling acid, the former was not obtained in a pure state in the last fraction, besides which, when these proportions were used, the acid of higher boiling point was not obtained in anything approaching a pure condition in the first fraction.

From the following experimental data, it will be seen that Wechsler's method does not give such good results as its author suggests, but although it cannot be regarded as a satisfactory method for the complete separation of mixtures of fatty acids, still the following details may be of interest, as showing in what cases and to what extent a separation is possible.

\section{Experimental.}

The acids under examination were obtained from Kahlbaum, and the purity of the portions used proved by submitting the acids to fractional distillation.

The following was the method of procedure adopted.

About 10 grams of the acid of lower boiling point were mixed with a molecular proportion of the higher boiling acid, 300 c.c. of water added, and the mixture exactly neutralised with caustic soda solution. After adding sulphuric acid (of such a strength that 1 c.c. was exactly equivalent to 1 c.c. of caustic soda) in sufficient amount to neutralise one-fifth of the caustic soda used, the whole was steam distilled, until the liquid passing over no longer reddened blue litmus paper. The distillate so obtained is spoken of as $\mathrm{F}_{1}$.

To the residue of the distillation, a further three-fifths of the sulphuric acid necessary to neutralise the caustic soda used was added, and VOL. LXXI.

R $\mathbf{R}$ 
the free acids distilled off with steam. The remaining one-fifth of the fatty acids was then set free by the addition of sulphuric acid, again distilling with steam. The distillate obtained is called $\mathbf{F}_{3}$.

The various distillates were treated as follows. After neutralisation with caustic soda and evaporation to a very small bulk, the sodium salts were decomposed with sulphuric acid, the free fatty acids extracted with pure ether, the ethereal solution dried over calcium chloride, and the residue distilled (not fractionally). A portion of the acid thus obtained was diluted with water, and after exact neutralisation with ammonium hydroxide, the silver salt was precipitated by silver nitrate, and collected with the aid of the pump, so as to remove as much of the mother liquor as possible ; it was then triturated with distilled water, again collected, repeatedly washed with water and dried, first on a porous plate, and finally over sulphuric acid in a vacuum. This differs slightly from the process adopted by Wechsler, inasmuch as he prepared the silver salts by boiling the distillate from the sterm distillation with silver carbonate.

As a first experiment, the separation of acetic and propionic acids was attempted. The first fraction contained pure propionic acid; but from the last fraction the following numbers were obtained.

$$
\begin{array}{cc}
\text { Found. } & \text { Calcnlated for } \mathrm{C}_{2} \mathrm{H}_{2} \mathrm{O}_{2} \mathrm{Ag} \text {. } \\
\mathrm{Ag} \text { (I) } 61.98 \text { (II) } 61.98 \text { per cent. } & 64.67 \text { per cent. }
\end{array}
$$

As these numbers do not agree with those obtained by Wechsler in a similar experiment, the purity of the acetic acid used was further tested by converting a portion into the silver salt, which on analysis gave the following numbers.

$$
\text { Found. }
$$

Ag 64.50 per cent.
Calculated for $\mathrm{C}_{2} \mathrm{H}_{8} \mathrm{O}_{2} \mathrm{Ag}$. 64.67 per cent.

All Wechsler's experiments, with the exception of the separation of

\begin{tabular}{|c|c|c|c|c|c|c|c|}
\hline Acids used. &  & 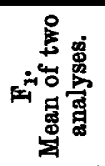 & 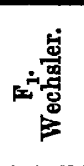 & $\begin{array}{l}\text { Calcu- } \\
\text { lated }\end{array}$ & 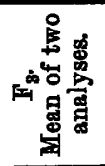 & 递 & $\begin{array}{l}\text { Calcu- } \\
\text { lated. }\end{array}$ \\
\hline $\begin{array}{l}\text { Acetic : Propionic .. } \\
\text { Acetic : Butyric...... } \\
\text { Acetic : iso-Butyric. } \\
\text { Propionic : Butyric } \\
\text { Butyric : iso-Valeric } \\
\text { Butyric : Hexoic.... }\end{array}$ & $\begin{array}{l}1: 1 \\
1: 1 \\
1: 1 \\
1: 1 \\
1: 1 \\
1: 1\end{array}$ & $\begin{array}{l}59 \cdot 73 \\
55 \cdot 26 \\
55 \cdot 61 \\
56 \cdot 16 \\
52 \cdot 72 \\
49 \cdot 36\end{array}$ & $\begin{array}{l}60 \cdot 08 \\
55 \cdot 70 \\
55 \cdot 47 \\
55 \cdot 75 \\
53 \cdot 74 \\
48 \cdot 61\end{array}$ & $\begin{array}{l}59 \cdot 66 \\
55 \cdot 38 \\
55 \cdot 38 \\
55 \cdot 38 \\
51 \cdot 67 \\
48 \cdot 43\end{array}$ & $\begin{array}{l}61 \cdot 98 \\
61 \cdot 73 \\
63 \cdot 85 \\
57 \cdot 83 \\
54 \cdot 31 \\
53 \cdot 68\end{array}$ & $\begin{array}{l}64 \cdot 14 \\
63 \cdot 77 \\
64 \cdot 45 \\
59 \cdot 18 \\
53 \cdot 80 \\
55 \cdot 08\end{array}$ & $\begin{array}{l}64 \cdot 67 \\
64 \cdot 67 \\
64 \cdot 67 \\
59 \cdot 66 \\
55 \cdot 38 \\
55 \cdot 38\end{array}$ \\
\hline
\end{tabular}
formic and acetic acids, were repeated, and the results, together with those obtained by the author, are given in the accompanying table, in which (and all subsequent tables) the numbers refer to the percentage of silver in the silver salts of the various acids. 
It was then thought that better results might be obtained for the last fraction, if, after distilling off the first fifth of liberated acid, instead of at once adding three-fifths of the necessary amount of sulphuric acid and distilling, the sulphuric acid wereadded in separate fifths, and the liberated fatty acid distilled off with steam after each addition.

A trial experiment made with acetic and iso-butyric acids confirmed this supposition, as the following numbers show :-

$\begin{array}{lllr} & & \text { Found. } & \text { Calculated for } \mathrm{C}_{4} \mathrm{H}_{7} \mathrm{O}_{2} \mathrm{Ag} . \\ \mathrm{F}_{1} & \mathrm{Ag} & 55 \cdot 63 \text { per cent. } & 55 \cdot 38 \text { per cent. } \\ \mathrm{F}_{5} & \mathrm{Ag} & \begin{array}{l}\text { Found. } \\ 64.51 \text { per cent. }\end{array} & \begin{array}{c}\text { Calculated for } \mathrm{C}_{2} \mathrm{H}_{3} \mathrm{O}_{2} \mathrm{Ag} . \\ 64.67 \text { per cent. }\end{array}\end{array}$

It is curious that this experiment affords the one single example where a complete separation of both fatty acids was effected. Comparing the results obtained when using the method giving fractions $F_{1}$ and $F_{3}$ and that giving $F_{1}$ and $F_{5}$ we have :

\begin{tabular}{|c|c|c|c|c|c|c|c|}
\hline Acids used. & 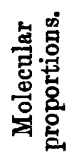 & 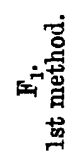 & 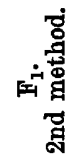 & $\begin{array}{l}\text { Calcu- } \\
\text { lated. }\end{array}$ & $\mathbf{F}_{3}$ & $F_{b}$. & $\begin{array}{l}\text { Calcu- } \\
\text { lated. }\end{array}$ \\
\hline Acetic : iso-Butyric. & $1: 1$ & $55 \cdot 61$ & $55 \cdot 63$ & $55 \cdot 38$ & $63 \cdot 85$ & $64 \cdot 51$ & $64 \cdot 67$ \\
\hline
\end{tabular}

The method of procedure in all experiments (including the above) from this point was therefore as follows :-

After exactly neutralising the mixture of fatty acids with caustic soda, one-fifth of the amount of sulphuric acid necessary to neutralise the caustic soda used was added, and the mixture distilled with steam. Distillate $=F_{1}$.

A 2nd fifth of canstic soda was added and distillation continued. Distillate $=F_{2}$.

$\triangle$ 3rd $" \quad " \quad\|\quad\| \quad \|=F_{3}$.

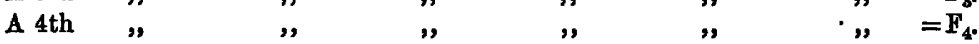

A 5th " " " " " $"$ "

Fractions $F_{2}, F_{3}$ and $F_{4}$ were rejected, $F_{1}$ and $F_{5}$ being the only ones examined. The following table gives the results of experiments made to further test the efficacy of this slight alteration in the detail of experiment ; they were unsatisfactory in every case.

\begin{tabular}{|c|c|c|c|c|c|}
\hline Acids used. & 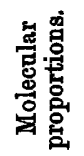 & $F_{1}$. & $\begin{array}{l}\text { Calcu- } \\
\text { lated. }\end{array}$ & $\mathbf{F}_{\text {s. }}$ & $\begin{array}{l}\text { Calcu- } \\
\text { lated. }\end{array}$ \\
\hline 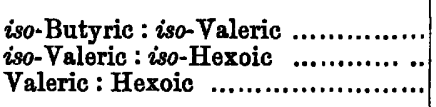 & $\begin{array}{l}1: 1 \\
1: 1 \\
1: 1\end{array}$ & $\begin{array}{l}52 \cdot 90 \\
49 \cdot 92 \\
49 \cdot 51\end{array}$ & $\begin{array}{l}51 \cdot 67 \\
48 \cdot 43 \\
48 \cdot 43\end{array}$ & $\begin{array}{l}53 \cdot 60 \\
50 \cdot 11 \\
51 \cdot 25\end{array}$ & $\begin{array}{l}55 \cdot 38 \\
51 \cdot 67 \\
51 \cdot 67\end{array}$ \\
\hline
\end{tabular}

R R 2 
As Wechsler invariably worked with mixtures of the fatty acids in molecular proportion, a few experiments were tried in which varying molecular proportions of the two acids were used, but again with unsatisfactory results, for both in the case of iso-valeric and iso-hexoic acids, as well as of iso-butyric and iso-valeric acids, when using three molecular proportions of the former to one of the latter, $F_{5}$ does not contain the lower boiling acid in an absolutely pure condition, and analyses of the silver salts made from the fractions $F_{1}$ point to a mixture of the two acids.

In the summary below are tabulated, for comparison, along with the results of the above experiments, those in which the same acids were used.in molecular proportion.



Chemical Laboratory,

ST. THOMAs's Hospitat. 